\title{
Article \\ A Rapid Method for the Determination of SBS Content Based on the Principle of Orthogonal Testing
}

\author{
Gang Xu, Xiaojing Gong, Yunhong Yu and Xianhua Chen * (D) \\ National Demonstration Center for Experimental Road and Traffic Engineering Education, School of \\ Transportation, Southeast University, 2 Sipailou, Nanjing 210096, China; 230198682@seu.edu.cn (G.X.); \\ 220194492@seu.edu.cn (X.G.); iiyyhong@163.com (Y.Y.) \\ * Correspondence: chenxh@seu.edu.cn
}

check for

updates

Citation: Xu, G.; Gong, X.; Yu, Y.; Chen, X. A Rapid Method for the Determination of SBS Content Based on the Principle of Orthogonal Testing. Appl. Sci. 2021, 11, 10911. https://doi.org/10.3390/ app112210911

Academic Editors: Amir Tabakovic, Jan Valentin, Liang He and Luís Picado Santos

Received: 15 August 2021

Accepted: 11 November 2021

Published: 18 November 2021

Publisher's Note: MDPI stays neutral with regard to jurisdictional claims in published maps and institutional affiliations.

Copyright: (c) 2021 by the authors. Licensee MDPI, Basel, Switzerland. This article is an open access article distributed under the terms and conditions of the Creative Commons Attribution (CC BY) license (https:/ / creativecommons.org/licenses/by/ $4.0 /)$.

\begin{abstract}
The performance of Styrene-butadiene-styrene (SBS) modified asphalt is closely related to the content of SBS modifier. In the production process of modified asphalt, a certain amount of additive such as sulfur and rubber oil may be added to reduce the segregation and promote the swelling of the polymer, but the effect of these additives on determining SBS content in asphalt is not yet clear. This paper presents the calibration curves of SBS content based on rutting factor and creep slope and points out its defects according to the temperature scanning test and the bending beam rheometer test. Subsequently, using Fourier transform infrared spectroscopy (FTIR) for rapid determination of polymer content in SBS modified asphalt based on orthogonal test and then the effects of additives such as asphalt type, SBS content, rubber oil and sulfur on the accuracy of polymer content determination by FTIR were investigated. Moreover, in the orthogonal tests of adding sulfur and rubber oil, the multivariate analysis of variance (MANOVA) was firstly used to analyze the additives influence on the test accuracy of FITR. Results indicated that the influencing degree of different additives is different. The influence of sulfur on the determination accuracy is greater than that of rubber oil. Therefore, the rapid determination method needs further improvement.
\end{abstract}

Keywords: SBS modified asphalt; high and low temperature performance; infrared spectroscopy; additives; orthogonal test

\section{Introduction}

By virtue of its excellent performance and environmental protection characteristics, SBS-modified asphalt has become the most commonly used modified asphalt around the world by blending SBS modifier and base asphalt [1-3]. SBS polymer is used as a dispersed phase and physically dispersed into the continuous phase of base asphalt. Due to the large differences between SBS polymer and matrix asphalt in chemical structure and physical parameters such as density, polarity, solubility, and molecular weight, SBS is distributed only in the form of particles in asphalt medium. It has a two-phase structure, which is an unstable thermodynamic incompatible system [4]. Therefore, in order to reduce the segregation and promote the swelling of the polymer in the production process of the modified asphalt, a certain amount of additive such as solubilizer and stabilizer may be added. The solubilizer usually uses petroleum distillate with high aromatic hydrocarbon content and low asphaltene content to improve the ratio of four components in the base asphalt [5-7]. The aromatic hydrocarbon can promote the dissolution of polystyrene blocks in the SBS polymer, making the SBS modifier more compatible with the matrix asphalt. Among all the solubilizers used in the market, rubber oil is widely accepted because of its low cost and good solubilizing performance. In terms of stabilizer, it is often used to improve the storage stability of SBS-modified asphalt and reduce the problem of segregation. The stabilizers currently used for SBS-modified asphalt mainly include the following four categories [8]: sulfur containing stabilizer, such as elemental sulfur and sulfur compounds, polyolefin stabilizer, like polyisobutene, inorganic acid and inorganic 
metal oxide stabilizers, such as phosphoric acid and zinc oxide, and inorganic clay stabilizer like montmorillonites and kaolin clay. Among them, sulfur-containing stabilizers, especially sulfur, stand out and are widely used in the industrial production of SBS-modified asphalt because of construction convenience, low requirements for equipment and low cost. It can be used directly after mixing with modified asphalt, and the vulcanization crosslinking reaction is mild and easy to control $[5,9,10]$.

SBS is a block polymer of polystyrene-polybutadiene-polystyrene. After being added to asphalt, it is sheared into fine particles and swelled, gradually forming a network-like crosslinked structure. The modification effect of asphalt will be affected by its content. Studies have shown that the microstructure of SBS modified asphalt is largely determined by the content of SBS [11]. The morphology and interaction between modified asphalt molecules will be different with a different SBS content, thus affecting the rheological properties and mechanical properties of modified asphalt. At present, the main methods to determine the modifier content of SBS-modified asphalt include fluorescence microscopy, gel permeation chromatography, chemical analysis, and infrared spectroscopy [12-15]. Fourier-Transform Infrared (FTIR) spectroscopy stands out among various methods, because of the simple test process, quick and easy operation, short data processing time and little error. Being able to quickly determine the content of SBS modifier with higher accuracy, it has become the main method for rapid determination of SBS content in engineering.

However, existing studies on the rapid determination of SBS content by FTIR had only considered a single factor of SBS content and had not considered the influence of admixtures on the test results $[16,17]$. Therefore, for the SBS modified asphalt with additives such as sulfur and rubber oil, the results of determining SBS content by FTIR may have a certain bias, and the accuracy is not known. It is necessary to design tests to explore the influence of additives on the accuracy of using FTIR to determine the polymer content in modified asphalt. For the case with multiple influencing factors, the commonly used test methods include comprehensive test and orthogonal test. Compared with comprehensive test, the orthogonal test can reduce test times and improve efficiency, which is essential for the cases with multiple influencing factors and levels.

Therefore, in view of this problem, this paper firstly analyzes the effect of SBS content on the high and low temperature performance of modified asphalt, and then establishes the calibration curve of SBS content and characteristic absorption peak absorbance in modified asphalt according to the infrared spectrum. Finally, the orthogonal test is designed, and the results are analyzed by the multivariate analysis of variance to explore the influence of additives on the determination results of SBS in modified asphalt.

\section{Experimental}

\subsection{Temperature Scanning Test by Dynamic Shear Rheometer}

The DSR (Dynamic Shear Rheometer) can be used to measure the complex shear modulus $\left(G^{*}\right)$ and phase angle $(\delta)$ of the asphalt binder at multiple temperatures to characterize the viscoelastic characteristics of the asphalt materials. At the same time, the rutting factor $\left(G^{*} / \sin \delta\right)$ is calculated and used as the main index to evaluate the high temperature performance of asphalt. The complex shear modulus $\left(G^{*}\right)$ can be considered to measure the total resistance to deformation of the asphalt when it is repeatedly sheared [18]. The higher the temperature, the smaller the complex shear modulus $\left(G^{*}\right)$ and the worse the anti-deforming capability of the asphalt. The phase angle $(\delta)$ is defined as the ratio of the time of strain hysteresis stress to the corresponding stress cycle in a loading cycle. It can be used to characterize the sensitivity of asphalt binders under certain temperature as environmental conditions change. The smaller the phase angle $(\delta)$, the more elastic the material. When $\delta=0^{\circ}$, the material is purely elastic; and When $\delta=90^{\circ}$, the material is purely viscous [18]. 


\subsection{Bending Beam Rheometer Test}

A BBR test was employed to characterize the low-temperature performance of SBS modified asphalt in all combinations according to ASTM D6648. The test temperature was $-12,-18{ }^{\circ} \mathrm{C}$ and the average results of three replicates were used as the testing results. Creep stiffness modulus $(S)$ and creep rate (m-value) was employed to characterize the low temperature performance. The greater the creep stiffness modulus $S$ value, the more elastic, less viscous and more brittle the asphalt, and the worse the low temperature resistance to deformation. The larger the creep slope $m$ value, the stronger the anti-deformation ability of the asphalt and the better the low temperature performance $[19,20]$.

\subsection{Infrared Spectroscopic Analysis}

The content of SBS in modified asphalt is quantitatively detected by infrared spectroscopy. As literature indicates, when continuous infrared light is irradiated on the material, the energy level transition occurs in the material molecules, and the substance absorbs infrared light of a specific wavelength to obtain a graph showing changes in absorbance at different wavelengths, which is an infrared spectrum. Its molecular structure is reflected by the infrared spectrum, thereby identifying heteroatom compounds in the asphalt and functional groups of SBS [17,21].

Generally, in the SBS modified asphalt, the base asphalt and the SBS modifier are physically mixed without chemical reaction, so the functional groups of the two do not disappear or add. In the modified asphalt, the vibration frequency of the SBS polymer molecules and the matrix asphalt molecules after infrared light irradiation is different, and the wavelengths of the infrared light absorption are also different, so the positions of the absorption peaks displayed on the infrared spectrum differ. For the modified asphalt with different SBS content, although the absorption peaks positions of the SBS polymer molecules and the matrix asphalt molecules are roughly the same in the infrared spectrum, their absorbance is not the same. Therefore, by comparing the absorption peaks of matrix asphalt and modified asphalt in the infrared spectrum, the existence of SBS modifier can be qualitatively identified and the content of modifier can be quantitatively analyzed [22].

Fourier infrared spectroscopy is based on Lambert-Beer law to achieve quantitative analysis of SBS modifier in modified asphalt as shown in Equation (1). Lambert-Beer law is that when a beam of light penetrates a sample of material, the absorbance at a certain wavenumber $(v)$ is related to the concentration and the optical path length of the material sample, i.e.,

$$
A(v)=\lg \left(\frac{1}{T(v)}\right)=a(v) b c
$$

where: $A(v)$ is the absorption intensity (absorbance) at wavenumber $v, T(v)$ is the transmittance at wavenumber $v, a(v)$ is the absorbance coefficient at wavenumber $v$, is the optical path length (the thickness of the sample, $\mathrm{mm}$ ), is the concentration of the material sample (\%).

Therefore, under the same test conditions, the characteristic absorption peak area ratio of SBS has linear relation with its content. The absorption peak area is selected as the characterization of absorption intensity in the infrared test. Infrared spectroscopy tests are carried out on a series of modified asphalt samples with known SBS content to establish a calibration curve of characteristic absorption peak area ratio and SBS content. By measuring the ratio of characteristic peak areas of SBS modified asphalt under the same test conditions the SBS content can be determined according to this calibration curve.

In order to establish the calibration curve of different SBS content, the matrix asphalt, SBS modifier and different modified asphalt samples with the SBS content of $2 \%, 4 \%, 6 \%$ are completely dissolved in tetrahydrofuran and titrated to $\mathrm{KBr}$ tablets. These tablets are placed in an oven at $60^{\circ} \mathrm{C}$ for $20 \mathrm{~min}$, and the infrared spectrum samples are prepared after the solvent is completely evaporated. By scanning each sample with an infrared spectrometer, the infrared spectrum is obtained. The spectral acquisition interval is $366 \sim 4000 \mathrm{~cm}^{-1}$ and the resolution is $2 \mathrm{~cm}^{-1}$. 


\subsection{Orthogonal Experimental Design}

Three factors including SBS, rubber oil and sulfur, which could influence the testing index of infrared spectroscopy, are considered in this paper. Each factor includes three levels of content, which are listed in Table 1. The properties of SBS-modified asphalt and base asphalt are listed in Table 2. Orthogonal tests can be used for multi-factor and multilevel tests. The orthogonal test is based on the orthogonality to select some representative points from the comprehensive test. These representative points have the characteristics of uniformity, dispersion and comparability, which can analyze the comprehensive influence of multiple factors with a small amount of test. It can reduce the number of tests, shorten the test period, and then improve the test efficiency. Therefore, for the case where there are many influencing factors and levels in this subject, the orthogonal test can not only reduce the number of tests, but also make the testing results intuitive and easy to analyze, which is of high rationality.

Table 1. Levels of different factors.

\begin{tabular}{cccc}
\hline Level & B (SBS Content/\%) & C (Sulfur Content/\%) & D (Rubber Oil Content/\%) \\
\hline I & $2 \%$ & $0.0 \%$ & $0 \%$ \\
II & $4 \%$ & $0.1 \%$ & $2 \%$ \\
III & $6 \%$ & $0.2 \%$ & $4 \%$ \\
\hline
\end{tabular}

Table 2. Properties of Asphalt.

\begin{tabular}{ccc}
\hline Test Parameters & SBS Modified Asphalt & Base Asphalt \\
\hline Penetration $\left(25^{\circ} \mathrm{C}, 100 \mathrm{~g}, 5 \mathrm{~s}\right) / 0.1 \mathrm{~mm}$ & 56 & 67.4 \\
Softening point $/{ }^{\circ} \mathrm{C}$ & 85.8 & 46.5 \\
Ductility $\left(5^{\circ} \mathrm{C}, 5 \mathrm{~cm} / \mathrm{min}\right) / \mathrm{cm}$ & 32 & - \\
Ductility $\left(15^{\circ} \mathrm{C}, 5 \mathrm{~cm} / \mathrm{min}\right) / \mathrm{cm}$ & & 115 \\
Mass change $/ \%$ & 0.11 & 0.04 \\
\hline
\end{tabular}

Three factors and three levels are involved in this study. Due to the repeated tests, the $\mathrm{L}_{9}\left(3^{3}\right)$ orthogonality table without blank columns can be used for the sake of simplicity. If the three-factor and three-level tests are carried out in accordance with the requirements of comprehensive test, $3^{3}=27$ combinations of tests must be carried out, and the parallel tests of each combination have not been considered. However, if the test is arranged according to the $\mathrm{L}_{9}\left(3^{3}\right)$ orthogonality table, only 9 rounds of tests need to be carried out, obviously reducing the workload. The factor level table is listed in Table 1.

\subsection{MANOVA}

The results of the orthogonal test are usually analyzed in two ways: direct-viewing analysis and analysis of variance (ANOVA). The direct-viewing analysis method is also called the range analysis method, which determines the primary and secondary relationships among the influencing factors by calculating the range of data and comparing its size. However, when the test results corresponding to different levels of a certain factor are different, the direct-viewing analysis method cannot distinguish whether this difference is caused by different levels of the factor or experimental errors. ANOVA can make up for the limitations of direct-viewing analysis and provide reliable analysis results [23]. ANOVA is usually used in the significance test for differences between two or more sample data, which is also known as $F$ test or analysis of variability [24]. Generally, due to the influence of various factors, the data obtained from the test will fluctuate. ANOVA can be used to evaluate the volatility of the test data and the influence of various factors on the test results to find certain regularity. ANOVA for orthogonal test can be carried out by SPSS (Statistical Program for Social Sciences) data analysis tool.

Therefore, this paper uses ANOVA to analyze the results of orthogonal tests. The orthogonal test is a multi-factor and single-index test. The influencing factors are SBS 
content, sulfur content and rubber oil content. It is assumed that the effects of the three are independent of each other and there is no correlation. Thus, the multi-factor univariate ANOVA model with no interaction in SPSS is used to compare and analyze the test results of three factors and three levels. Multivariate analysis of variance (MANOVA) uses the $F$ test, whose null hypothesis is $\mathrm{H}_{0}$ : the observed variable values at different levels of each factor have no significant difference. SPSS will automatically calculate the F value and provide the corresponding probability $p$ value according to the $F$ distribution table. It can be judged whether the different levels of each factor have a significant influence on the observed variables by comparing the $p$ value with the magnitude of the significance level $\alpha$.

\section{Results and Discussion}

\subsection{Rheological Test Results}

\subsubsection{Temperature Scanning Test Results}

The temperature sweep test is carried out on different virgin SBS modified asphalt samples by DSR. The complex shear modulus $G^{*}$ and phase angle $\delta$ of three modified asphalt at multiple temperatures are measured to calculate the rutting factor $G^{*} / \sin \delta$. According to the test results, the curves of rutting factor $G^{*} / \sin \delta$ with temperature under different SBS content are plotted, as shown in Figure 1.

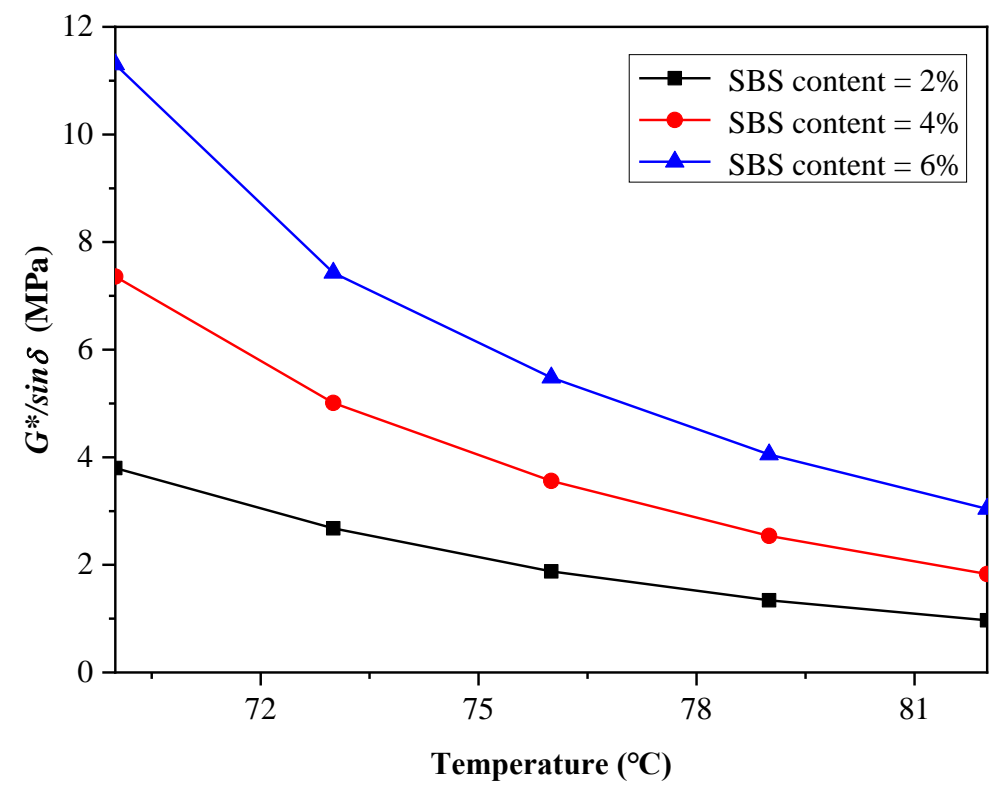

Figure 1. Curves of rutting factor with temperature under different SBS content.

Figure 2 reflects the temperature curves of rutting factor $G^{*} / \sin \delta$ of the three modified asphalt. With the increase of the modifier content, the $G^{*} / \sin \delta$ value of the modified asphalt increases; and as the test temperature increases, the $G^{*} / \sin \delta$ value tends to decrease. This means that the higher the SBS content, the lower the temperature, and the larger the value of $G^{*} / \sin \delta$, indicating that the asphalt is more elastic, the high-temperature flow deformation is smaller, the high-temperature performance is better, and the anti-rutting ability is stronger.

The high temperature performance index of modified asphalt increases with the increase of SBS content, indicating that the higher the SBS content, the better the high temperature performance of the modified asphalt. This is because SBS polymer and matrix asphalt are two completely different materials. SBS is dispersed as particulates in the matrix asphalt under mechanical force. With a different SBS content, SBS has a different distribution in the asphalt. When the SBS content is small, SBS is scattered as a dispersed phase in the continuous asphalt phase. When the SBS content is high, the SBS dispersed phase forms a network structure in the asphalt. If the SBS content is continuously increased, 
the asphalt will change phase. Therefore, the larger the content of SBS, the more uniform it is distributed in the asphalt. The formation of a three-dimensional network structure can well limit the movement of the entire molecular system of the modified asphalt at high temperature, thereby improving the high temperature performance of the asphalt.

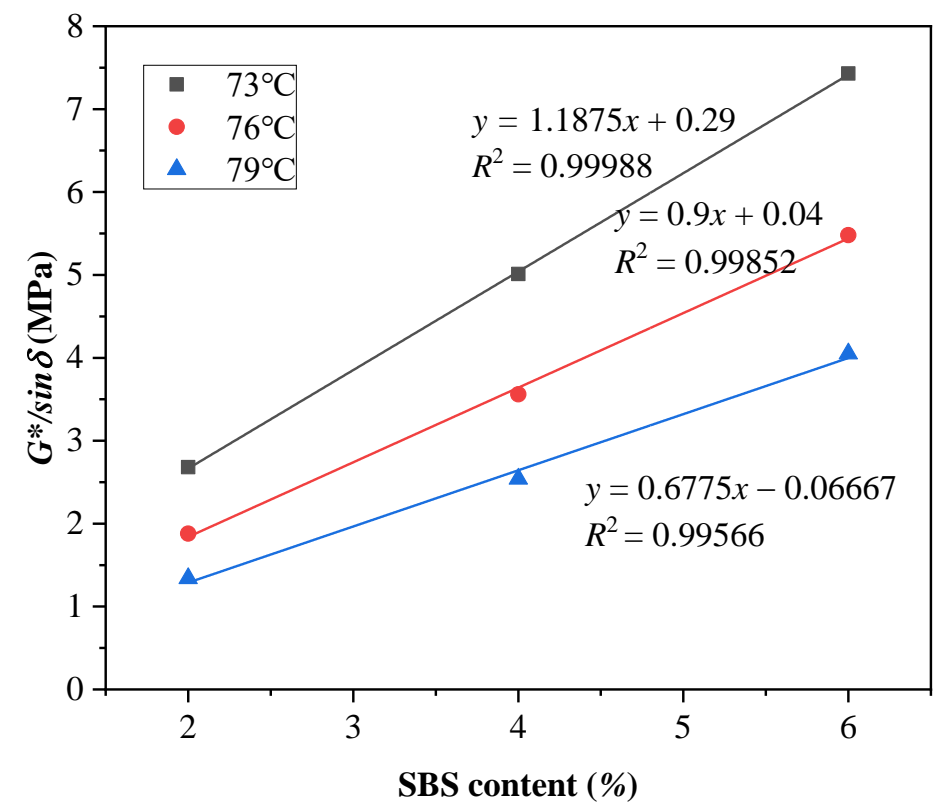

Figure 2. Calibration curves of SBS content based on rutting factor.

According to the SBS content and the calculation results of rutting factor, the fitting curves of $G^{*} / \sin \delta$ value and SBS content at different test temperatures can be drawn, taking $73{ }^{\circ} \mathrm{C}, 76{ }^{\circ} \mathrm{C}$ and $79{ }^{\circ} \mathrm{C}$ as examples, as shown in Figure 2. It is obvious that the rutting factor has a good linear relation with the SBS content at different temperatures, which can be used for the calibration of SBS content in modified asphalt. However, the good linear relation is related to temperature. The rutting factor increases linearly with the increase of SBS content at different temperatures, but its growth slope is significantly different. When using this result to determine the SBS content in the modified asphalt, the specific calibration curve at the actual temperature of the asphalt needs to be found. So, this method is not simple. In addition, there is another problem with the determination of SBS content in modified asphalt using a calibration curve based on the rutting factor: this method is susceptible to other modifiers in the asphalt. Due to the high market price of SBS, some modified asphalt manufacturers privately reduce the SBS content and add some cheap modifiers to reduce the cost for personal gain. This makes the rutting factor value of the produced SBS modified asphalt can also meet the requirements of the specification, but its road performance is unknown. In this case, the SBS content measured by the calibration curve based on the rutting factor is qualified with a quite different truth.

\subsubsection{Bend Beam Rheometer Test Results}

The creep stiffness modulus $S$, creep rate $m$ of the matrix asphalt and the three modified asphalts in long-term aging were determined by bending beam rheometer at different test temperatures. The test results are recorded in Table 3.

According to the above test results, the linear fitting curves of the stiffness modulus $S$ and the creep slope $m$ with the SBS content at different test temperatures are plotted respectively, as shown in Figure 3. It is obvious that at $-18{ }^{\circ} \mathrm{C}$, the creep stiffness $S$ of modified asphalt decreases with the increase of the SBS content, which indicates that as the SBS content increases, the asphalt becomes more elastic, more viscous and less brittle, and the resistance to deformation increases. At $-12{ }^{\circ} \mathrm{C}$, although the $S$ value of modified asphalt is smaller than that of matrix asphalt, its variation with the SBS content is not stable. 
At the same time, the creep stiffness $m$ value of modified asphalt is lower than that of matrix asphalt at both test temperatures, both decreasing with the increase of SBS content. Moreover, when the SBS content is the same, the lower the test temperature, the lower the $m$ value, which means that with the decrease of temperature, the anti-deformation ability of the asphalt decreases, and the low temperature performance becomes worse.

Table 3. BBR test results.

\begin{tabular}{cccc}
\hline Temperature $\left({ }^{\circ} \mathbf{C}\right)$ & SBS Content & $S$ (MPa) & $m$ \\
\hline \multirow{3}{*}{-12} & $0 \%$ & 125 & 0.420 \\
& $2 \%$ & 102 & 0.417 \\
$4 \%$ & 109 & 0.409 \\
& $6 \%$ & 103 & 0.387 \\
\hline \multirow{2}{*}{-18} & $0 \%$ & 387 & 0.287 \\
& $2 \%$ & 256 & 0.329 \\
& $4 \%$ & 232 & 0.314 \\
& $6 \%$ & 209 & 0.298 \\
\hline
\end{tabular}

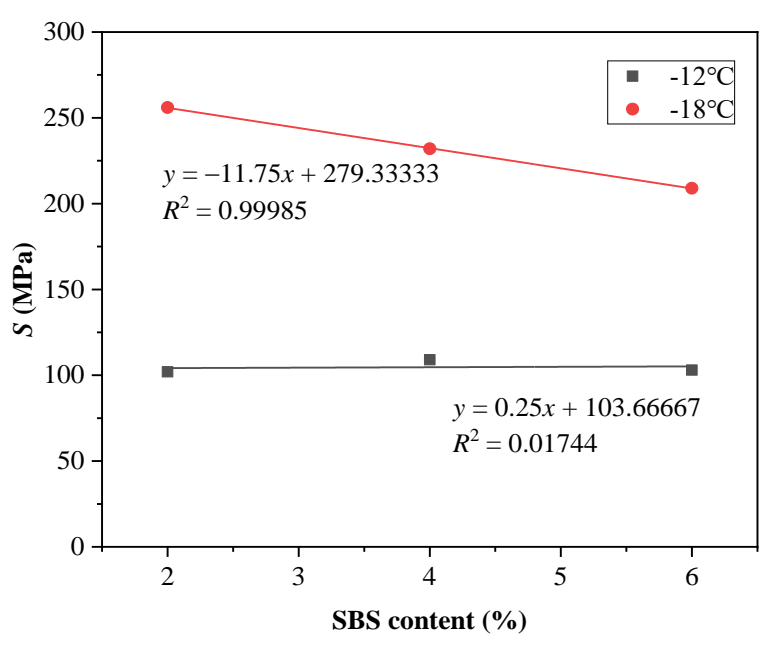

(a)

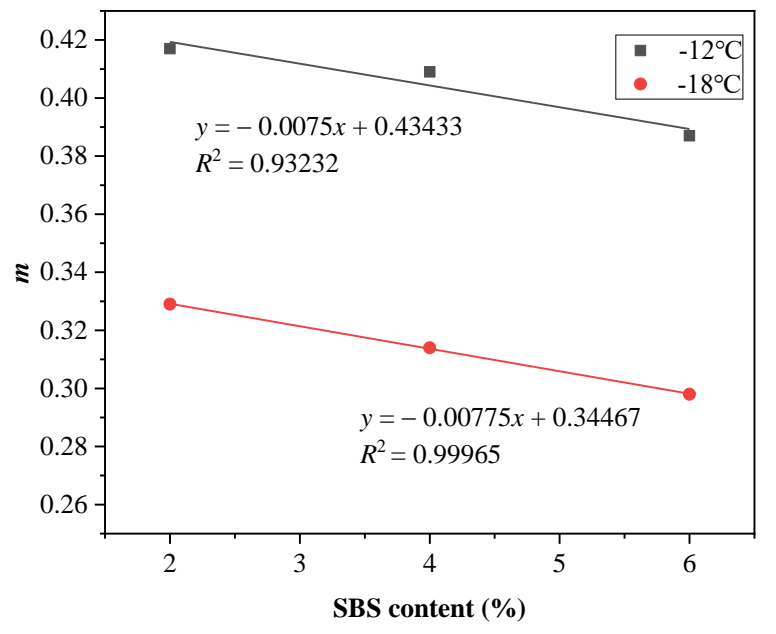

(b)

Figure 3. Calibration curves of SBS content based on (a) stiffness modulus $S$ and (b) creep slope $m$.

It can be seen from the figures that the linear fitting results of creep slope $m$ with SBS content at both test temperatures are more precise. The stiffness modulus $S$ and SBS content also have a good linear relation at $-18{ }^{\circ} \mathrm{C}$, but the linear fitting results at $-12{ }^{\circ} \mathrm{C}$ are not accurate. This is because, as can be seen from Table 3 the stiffness modulus of the matrix asphalt has reached $125 \mathrm{MPa}$ at $-12{ }^{\circ} \mathrm{C}$, which is not much different from that of the modified asphalt after the addition of $2 \%$ modifier. Therefore, the change of $S$ value with the increase of the amount at $-12{ }^{\circ} \mathrm{C}$ is not obvious. The fitting result of creep slope $m$ with SBS content can be used to calibrate the SBS content in modified asphalt, but the good linear relation of the result is also related to temperature, which means the calibration curves differ at different temperatures. The problem with this method is also the same as the calibration method based on the rutting factor.

\subsection{FTIR Test Results}

\subsubsection{Analysis of FTIR Test Results}

The infrared spectrum of each sample is obtained by scanning it with an infrared spectrometer. Figure 4 shows the infrared spectrum of matrix asphalt, SBS, rubber oil and SBS-modified asphalt in the wave number region between $500-1400 \mathrm{~cm}^{-1}$. Comparing the infrared spectrum of matrix asphalt and SBS modifier, it can be found that the methyl 
and methylene groups in matrix asphalt produce a characteristic absorption peak near $1377 \mathrm{~cm}^{-1}$, which is not affected by SBS modifier because SBS does not have this peak. The infrared spectrum of SBS has two strong absorption peaks, one is formed by the out-ofplane rocking vibration of $\mathrm{C}-\mathrm{H}$ (polystyrene) in benzene ring at $699 \mathrm{~cm}^{-1}$, and the other is formed by the out-of-plane rocking vibration of trans-butadiene $=\mathrm{CHC}_{2}$ (polybutadiene) at $966 \mathrm{~cm}^{-1}$ [25].

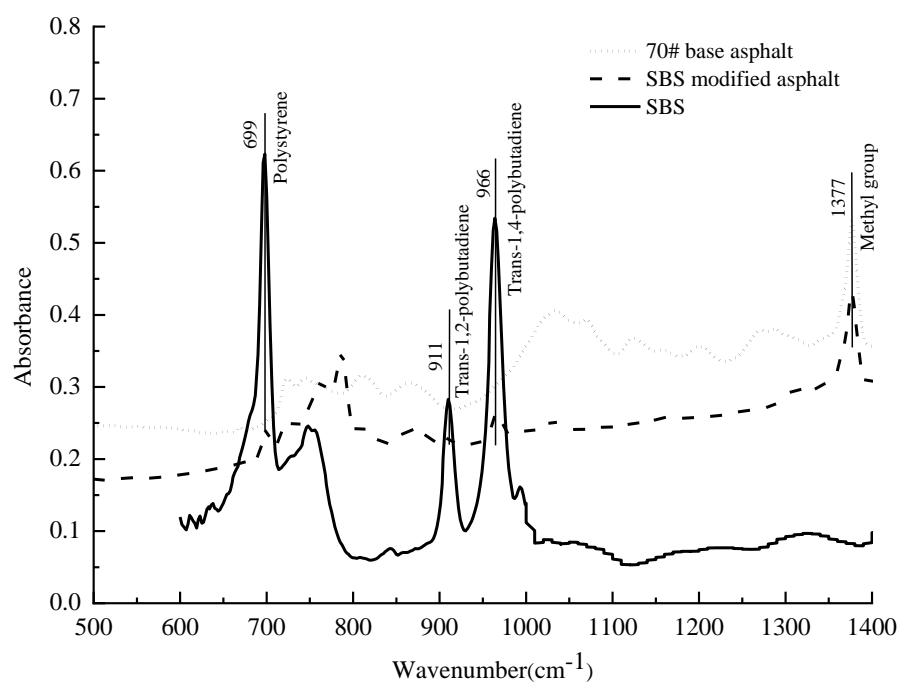

Figure 4. Infrared spectrum of SBS, base asphalt, rubber oil and SBS modified asphalt.

Since the SBS modifier is physically compatible with matrix asphalt, the infrared spectrum of SBS-modified asphalt is a simple superposition of that of SBS and base asphalt, where no new peaks appear, or existing peaks disappear [13]. It can be seen from Figure 4 that the modified asphalt retains the SBS characteristic absorption peaks at $699 \mathrm{~cm}^{-1}$ and $966 \mathrm{~cm}^{-1}$, as well as a characteristic absorption peak of matrix asphalt at $1377 \mathrm{~cm}^{-1}$. The absorption peaks of modified asphalt at $699 \mathrm{~cm}^{-1}$ and $966 \mathrm{~cm}^{-1}$ can be used to judge the existence of SBS modifier, and the SBS content can be quantitatively analyzed according to the intensity of the absorption peak.

Figure 5 is the infrared spectrum of the modified asphalt with different SBS content. The peak area of the absorption peak at $699 \mathrm{~cm}^{-1}$ and $966 \mathrm{~cm}^{-1}$ has a certain relationship with SBS modifier content, and the intensity of the three absorption peaks does not affect each other. Therefore, the content of SBS modifier can be quantitatively analyzed based on the ratio of the absorption peak area at $699 \mathrm{~cm}^{-1}, 966 \mathrm{~cm}^{-1}$ and $1377 \mathrm{~cm}^{-1}$ in the infrared spectrum of the modified asphalt.

The absorbance $A$ is measured by spectral peak area. In this paper, the ratio of characteristic peak area at $699 \mathrm{~cm}^{-1}$ to that at $1377 \mathrm{~cm}^{-1}$ is $A_{1}$, and the ratio of the peak area at $966 \mathrm{~cm}^{-1}$ to that at $1377 \mathrm{~cm}^{-1}$ is $A_{2}$, i.e.,

$$
\begin{aligned}
& A_{1}=\frac{\text { peak area (intensity) at } 699 \mathrm{~cm}^{-1}}{\text { peak area (intensity) at } 1377 \mathrm{~cm}^{-1}} \\
& A_{2}=\frac{\text { peak area (intensity) at } 966 \mathrm{~cm}^{-1}}{\text { peak area (intensity) at } 1377 \mathrm{~cm}^{-1}}
\end{aligned}
$$

Without any other additives, two kinds of base asphalt (SK70\# and Zhongshiyou asphalt) are used to respectively prepare SBS-modified asphalt with the SBS content of $2 \%, 4 \%$ and $6 \%$. Five sets of parallel tests were conducted for each content. By using the OMNIC software reading tool to read the absorbance value the infrared spectrum of these two modified asphalt groups and the two kinds of matrix asphalt is determined. The standard curves of characteristic absorption peak area ratio $A_{1}, A_{2}$ and SBS content are drawn, as shown in Figure 6. 


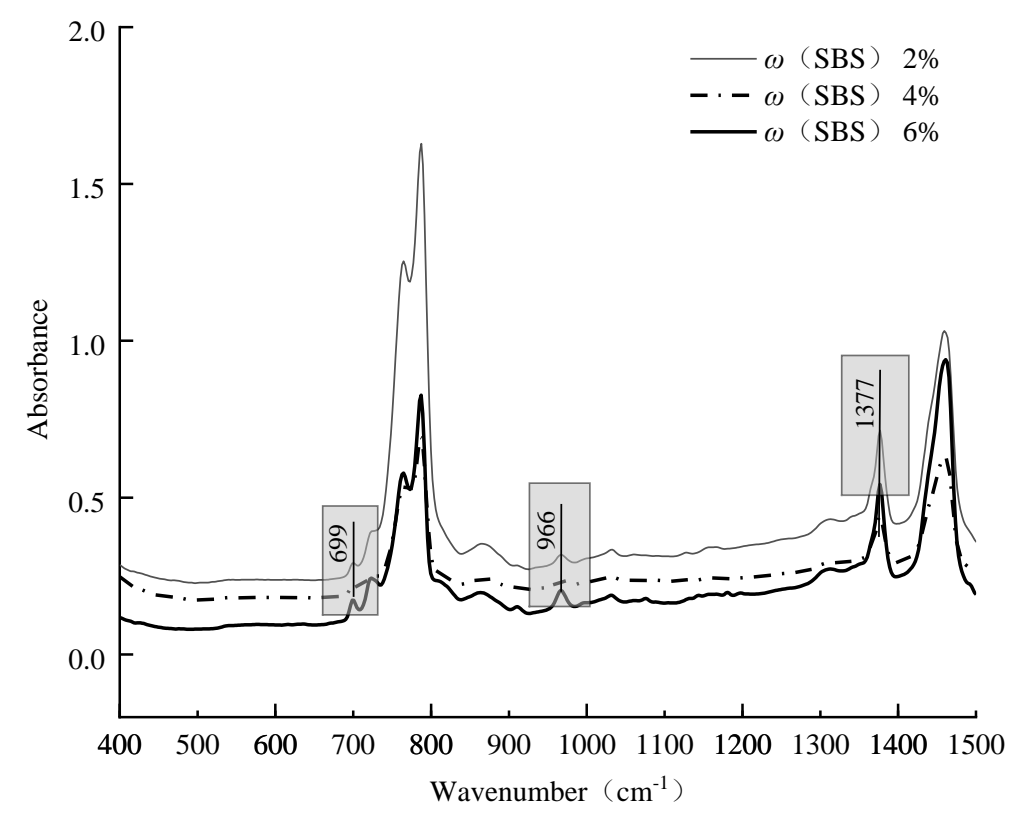

Figure 5. Infrared spectrum of SBS modified asphalt with different SBS content.

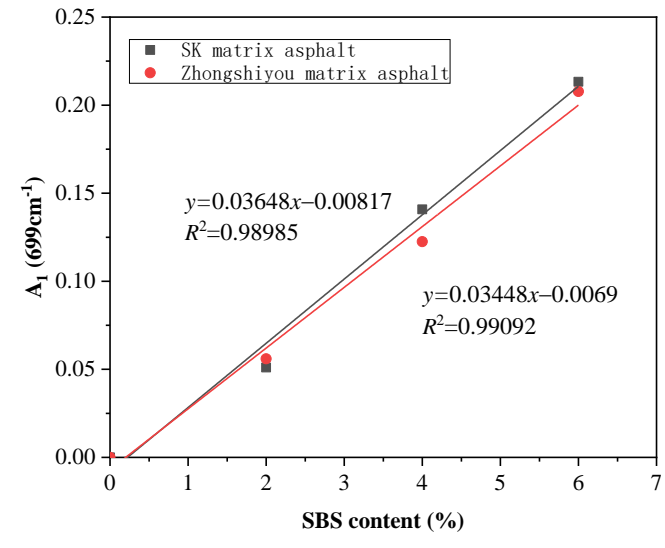

(a)

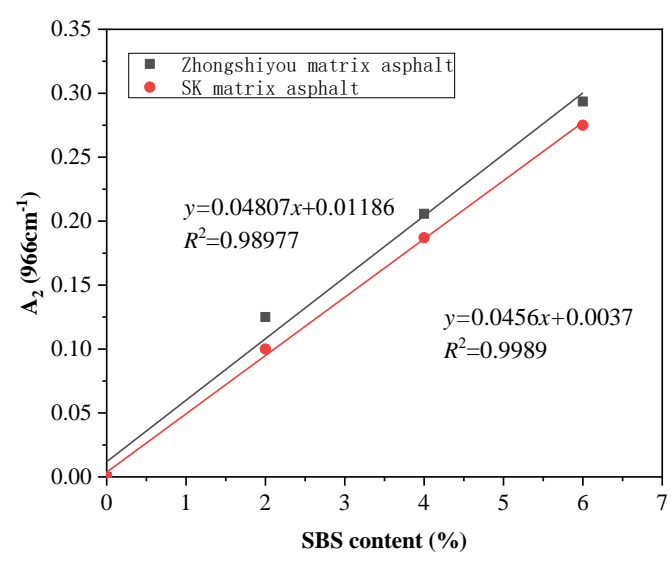

(b)

Figure 6. Standard curves of $A$ value with SBS content at different absorbance (a) $699 \mathrm{~cm}^{-1}$ and (b) $966 \mathrm{~cm}^{-1}$.

Regardless of the type of matrix asphalt, the $A_{1}$ and $A_{2}$ values at $699 \mathrm{~cm}^{-1}$ and $966 \mathrm{~cm}^{-1}$ also increase with the increase of SBS content. The $A$ value has a good linear relation with the SBS content, and the correlation coefficient is very close to 1 , it is consistent with the results of existing studies [16,17]. Both the $A_{1}$ and $A_{2}$ values can be used as the basis for determining the SBS content in modified asphalt with the correlation not being affected by the type of matrix asphalt. However, the standard equations of the two kinds of base asphalt are quite different, so the original matrix asphalt must be obtained when using this method to determine SBS content, and it cannot be replaced by matrix asphalt of different sources.

\subsubsection{Analysis Impact of Additives Based on Orthogonal Test}

According to the orthogonality table, nine kinds of modified asphalt are prepared by $0.0 \%, 0.1 \%, 0.2 \%$ sulfur combined with $0 \%, 2 \%, 4 \%$ rubber oil. Five parallel samples are prepared for each kind of modified asphalt. FTIR test is carried out on each sample, reading the corresponding absorption peak areas and calculating the infrared spectrum $A$ value as a test index. The test plan is listed in Table 4. 
Table 4. Orthogonal test plan.

\begin{tabular}{ccccc}
\hline Test Number & $\begin{array}{c}\text { B (SBS } \\
\text { Content/\%) }\end{array}$ & $\begin{array}{c}\text { C (Sulfur } \\
\text { Content/\%o) }\end{array}$ & $\begin{array}{c}\text { D (Rubber Oil } \\
\text { Content/\%) }\end{array}$ & Test Plan \\
\hline 1 & 2 & 0 & 0 & $\mathrm{~B}_{1} \mathrm{C}_{1} \mathrm{D}_{1}$ \\
2 & 2 & 1 & 2 & $\mathrm{~B}_{1} \mathrm{C}_{2} \mathrm{D}_{2}$ \\
3 & 2 & 2 & 4 & $\mathrm{~B}_{1} \mathrm{C}_{3} \mathrm{D}_{3}$ \\
4 & 4 & 0 & 2 & $\mathrm{~B}_{2} \mathrm{C}_{1} \mathrm{D}_{2}$ \\
5 & 4 & 1 & 4 & $\mathrm{~B}_{2} \mathrm{C}_{2} \mathrm{D}_{3}$ \\
6 & 4 & 2 & 0 & $\mathrm{~B}_{2} \mathrm{C}_{3} \mathrm{D}_{1}$ \\
7 & 6 & 0 & 4 & $\mathrm{~B}_{3} \mathrm{C}_{1} \mathrm{D}_{3}$ \\
8 & 6 & 1 & 0 & $\mathrm{~B}_{3} \mathrm{C}_{2} \mathrm{D}_{1}$ \\
9 & 6 & 2 & 2 & $\mathrm{~B}_{3} \mathrm{C}_{3} \mathrm{D}_{2}$ \\
\hline
\end{tabular}

Taking $A_{1}$ and $A_{2}$ values as the test indexes, MANOVA is conducted on the orthogonal test results respectively using SPSS21.0, which adopts the system default significance level $\alpha=0.05$. The results of MANOVA are listed in Tables 5 and 6 , which show the calibration model test in ANOVA. The original hypothesis is that the SBS content, sulfur content and rubber oil content in the model have no effect on $A$ value that is the test index. If the probability $p$ value is less than the significance level $\alpha$, it means that the variance model is statistically significant, that is, at least one of the three influencing factors has a significant influence on the $A$ value.

Table 5. Inter-subject effect test of three factors.

\begin{tabular}{cccccc}
\hline Source & $\begin{array}{c}\text { Type III Sum of } \\
\text { Squares }\end{array}$ & df & $\begin{array}{c}\text { Mean } \\
\text { Square }\end{array}$ & F & $p$ \\
\hline Corrected Model & $0.152^{\mathrm{a}}$ & 6 & 0.025 & 131.704 & $1.000 \times 10^{-13}$ \\
Intercept & 0.474 & 1 & 0.474 & 2462.990 & $1.000 \times 10^{-13}$ \\
SBS content & 0.145 & 2 & 0.072 & 376.333 & $1.000 \times 10^{-13}$ \\
Sulfur content & 0.004 & 2 & 0.002 & 10.373 & $2.771 \times 10^{-4}$ \\
Rubber oil content & 0.002 & 2 & 0.001 & 6.094 & $5.255 \times 10^{-13}$ \\
Error & 0.007 & 36 & 0.000 & - & - \\
Total & 0.642 & 43 & - & - & - \\
Corrected Total & 0.159 & 42 & - & - & - \\
${ }^{a} . R^{2}=0.956$ (Adjusted $\left.\mathrm{R}^{2}=0.949\right)$, Dependent Variable: $A_{1}$ Value $\left(699 \mathrm{~cm}^{-1}\right)$. &
\end{tabular}

Table 6. Inter-subject effect test of three factors.

\begin{tabular}{cccccc}
\hline Source & $\begin{array}{c}\text { Type III Sum of } \\
\text { Squares }\end{array}$ & df & $\begin{array}{c}\text { Mean } \\
\text { Square }\end{array}$ & F & $\boldsymbol{p}$ \\
\hline Corrected Model & $0.246^{\mathrm{a}}$ & 6 & 0.041 & 162.999 & $1.000 \times 10^{-13}$ \\
Intercept & 1.533 & 1 & 1.533 & 6093.735 & $1.000 \times 10^{-13}$ \\
SBS content & 0.222 & 2 & 0.111 & 441.598 & $1.000 \times 10^{-13}$ \\
Sulfur content & 0.017 & 2 & 0.008 & 33.542 & $1.000 \times 10^{-13}$ \\
Rubber oil content & 0.005 & 2 & 0.002 & 9.867 & $1.000 \times 10^{-13}$ \\
Error & 0.009 & 36 & 0.000 & - & - \\
Total & 1.824 & 43 & - & - & - \\
Corrected Total & 0.255 & 42 & - & - & - \\
\hline
\end{tabular}

a. $\mathrm{R}^{2}=0.964$ (Adjusted $\left.\mathrm{R}^{2}=0.959\right)$, Dependent Variable: $A_{2}$ Value $\left(966 \mathrm{~cm}^{-1}\right)$.

1. $A_{1}$ value as the test index

Comparing the $p$ value with the significance level $\alpha=0.05$, it can be known whether each factor has a significant influence on the observation results, while the comparison of $F$ value shows the influencing degree of each factor. It can be seen from Table 5 that the $p$ values of SBS content, sulfur content and rubber oil content are much smaller than the significance level $\alpha$, indicating that these three factors have significant influence on the infrared spectrum absorbance $A_{1}$ value. However, it's quite different from the influencing 
degree of the three factors. Table 5 showed $F_{B}>F_{C}>F_{D}$, the $F$ value of SBS content is 376.333 , which is much larger than that of sulfur and rubber oil content, and the $F$ value of sulfur content is also larger than that of rubber oil content. It indicates that the most influential factor for the absorbance $A_{1}$ value is the SBS content, followed by sulfur content and rubber oil content.

2. $A_{2}$ value as the test index

Similarly, as can be seen from the results of MANOVA in Table 6, for the absorbance $A_{2}$ value, the probability $p$ values of SBS content, sulfur content and rubber oil content are all close to 0 , all significantly less than the significance level $\alpha=0.05$, which means all these three factors have significant influence on the $A_{2}$ value. According to the critical value of the 3-factor significance level $\alpha=0.05$ for the 2 degrees of freedom is $F_{(2,3) 0.05}=19.164$, Table showed $F_{\text {sbs }}=441.598>F_{(2,3) 0.05}, F_{\text {sulfur }}=33.542>F_{(2,3) 0.05}, F_{\text {rubber oil }}=9.867<F_{(2,3) 0.05}$. Moreover, comparing the $F$ values of the three factors, it is found that the $F$ value of SBS content is much larger than that of sulfur content and rubber oil content, and the $F$ value of sulfur content is also larger than that of rubber oil content. This means that the influence of these three factors on the absorbance $A_{2}$ value is different, which is the same as the case where the $A_{1}$ value is the test index. In order of their effect, SBS content is the largest, sulfur content followed, and rubber oil content is the smallest. Furthermore, Using SPSS to remove the effects of other variables, the marginal mean was estimated at different levels of each factor and was shown in Figure 7 . Figure 7 illustrated that the $\mathrm{A}_{2}$ increased when the content of SBS and rubber oil increased, but reduced when the content of sulfur increased. Therefore, at the significance level $\alpha=0.05$, the three factors of SBS content, sulfur content and rubber oil content have significant influence on the $A_{1}$ and $A_{2}$ values, which are the characteristic peak area ratios of SBS-modified asphalt at $669 \mathrm{~cm}^{-1}$ and $966 \mathrm{~cm}^{-1}$ in the infrared spectrum. The influencing degree is both: SBS content $>$ sulfur content $>$ rubber oil content. This means under different SBS content, the addition of sulfur and rubber oil will have a significant effect on the accuracy of FTIR test results, and the influencing degree of sulfur is greater than that of rubber oil. The reason may be that the rubber oil added to the modified asphalt promotes the cross-linking of SBS polymer without changing the characteristic functional groups in SBS. However, after the addition of sulfur, the double bond of polybutadiene block in the SBS polymer reacts with the hetero atom in asphalt to form SBS-asphalt grafts, which changes the characteristic functional groups in SBS, thereby affecting the magnitude of $A$ value. Therefore, the method of rapidly determining the SBS content in modified asphalt by infrared spectroscopy needs to be further improved.

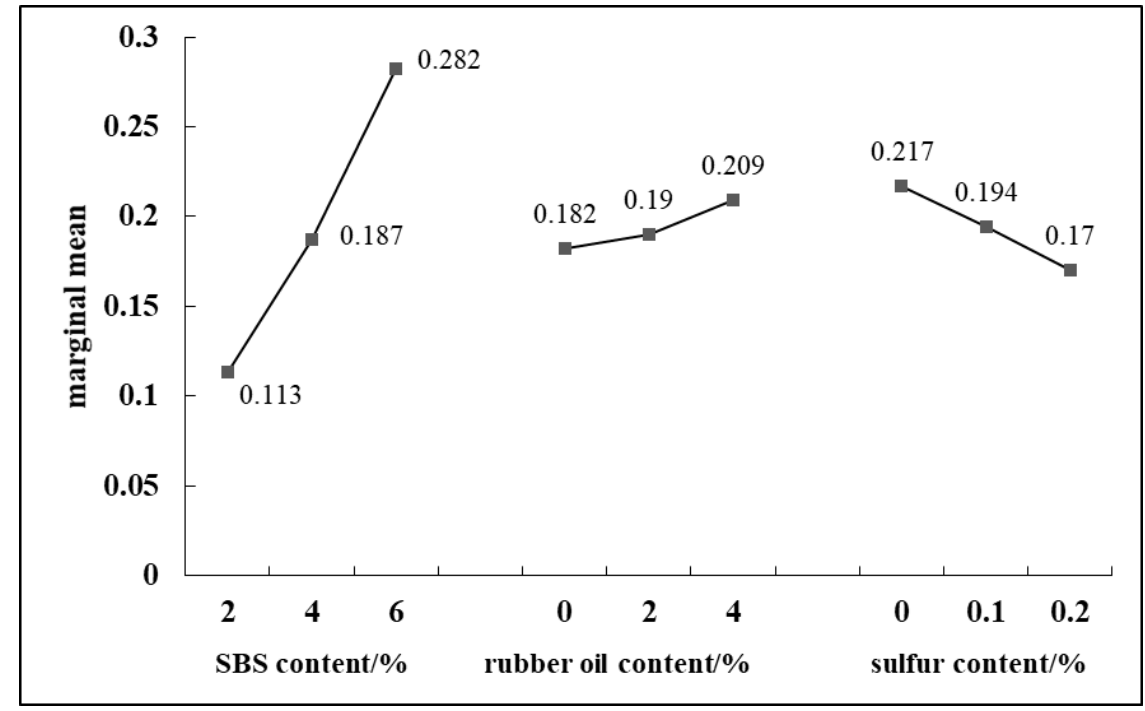

Figure 7. Marginal mean of all three factors. 


\section{Conclusions}

In this paper, based on temperature shear test and bending beam rheological test, the influence of SBS content on the high and low temperature performance of modified asphalt is preliminarily analyzed. The calibration curves of SBS content based on rutting factor and creep slope are presented and its defects are pointed out. Meanwhile, the calibration curve of determining SBS content by FTIR is established, and the orthogonal test is designed to explore the influence of additives sulfur and rubber oil on the determination results. The main conclusions are as follows:

(1) The rutting factor $G^{*} / \sin \delta$ and the creep slope $m$ both have a good linear relation with the SBS content. The calibration curves of the two indexes can be used to determine the SBS content in modified asphalt. However, the linear fitting of these two factors is related to temperature, and the determination results are also susceptible to other modifiers in the asphalt, so it is not worth promoting.

(2) It can be seen from the infrared spectrum that the SBS modified asphalt retains the characteristic absorption peaks of SBS modifier at $699 \mathrm{~cm}^{-1}$ and $966 \mathrm{~cm}^{-1}$, as well as the characteristic peak of matrix asphalt at $1377 \mathrm{~cm}^{-1}$. The area of the absorption peaks at $699 \mathrm{~cm}^{-1}$ and $966 \mathrm{~cm}^{-1}$ has a certain relationship with the SBS modifier content. Thus, the characteristic peak area at $1377 \mathrm{~cm}^{-1}$ can be used as a reference to respectively establish the linear regression curve of SBS content and the ratio of the absorption peak area at $699 \mathrm{~cm}^{-1}$ and $966 \mathrm{~cm}^{-1}$ to that at $1377 \mathrm{~cm}^{-1}$. It can well predict the content of the modifier in SBS modified asphalt.

(3) In the orthogonal tests, MANOVA is used to analyze the effect of different additives on the determination results. It is found that at the significance level $\alpha=0.05$, the additive sulfur and rubber oil have significant effect on the determination of SBS content in modified asphalt by FTIR, and the influence of sulfur content is greater than that of rubber oil. Therefore, the FTIR method for rapid determination of SBS content in modified asphalt needs to be further improved.

Author Contributions: Conceptualization, G.X. and X.C.; methodology, X.G.; validation, X.C., Y.Y.; formal analysis, X.G.; investigation, G.X.; resources, X.C.; data curation, X.G.; writing-original draft preparation, G.X.; writing-review and editing, X.G. and Y.Y.; supervision, X.C.; project administration, X.C.; funding acquisition, X.C. All authors have read and agreed to the published version of the manuscript.

Funding: This research was funded by National Natural Science Foundation of China (No. 51778136), Technology Research and Development Program of China State Railway Group Co., Ltd. (K2020G032). And the APC was funded by Technology Research and Development Program of China State Railway Group Co., Ltd., Beijing, China.

Institutional Review Board Statement: Not applicable.

Informed Consent Statement: Not applicable.

Data Availability Statement: Not applicable.

Conflicts of Interest: The authors declare no conflict of interest.

\section{References}

1. Stangl, K.; Jaeger, A.; Lackner, R. The effect of styrene-butadiene-styrene modification on the characteristics and performance of bitumen. Monatsh. Chem. 2007, 138, 301-307. [CrossRef]

2. Larsen, D.O.; Alessandrini, J.L.; Bosch, A.; Cortizo, M.S. Micro-structural and rheological characteristics of SBS-asphalt blends during their manufacturing. Constr. Build. Mater. 2009, 23, 2769-2774. [CrossRef]

3. Liang, M.; Liang, P.; Fan, W.; Qian, C.; Xin, X.; Shi, J.; Nan, G. Thermo-rheological behavior and compatibility of modified asphalt with various styrene-butadiene structures in SBS copolymers. Mater. Design. 2015, 88, 177-185. [CrossRef]

4. Lin, P.; Huang, W.; Li, Y.; Tang, N.; Xiao, F. Investigation of influence factors on low temperature properties of SBS modified asphalt. Constr. Build. Mater. 2017, 154, 609-622. [CrossRef]

5. Jin, H.L.; Gao, G.T.; Zhang, Y.; Zhang, Y.X.; Sun, K.; Fan, Y.Z. Improved properties of polystyrene-modified asphalt through dynamic vulcanization. Polym. Test. 2002, 21, 633-640. [CrossRef] 
6. Huang, W.; Tang, N. Characterizing SBS modified asphalt with sulfur using multiple stress creep recovery test. Constr. Build. Mater. 2015, 93, 514-521. [CrossRef]

7. Aguirre de Carcer, I.; Masegosa, R.M.; Teresa Vinas, M.; Sanchez-Cabezudo, M.; Salom, C.; Prolongo, M.G.; Contreras, V.; Barcelo, F.; Paez, A. Storage stability of SBS/sulfur modified bitumens at high temperature: Influence of bitumen composition and structure. Constr. Build. Mater. 2014, 52, 245-252. [CrossRef]

8. Yang, L. Research progress of SBS modified asphalt stabilizer. Shanxi Transp. Technol. 2013, 4, 1-2.

9. Zhang, F.; Yu, J.; Wu, S. Effect of ageing on rheological properties of storage-stable SBS/sulfur-modified asphalts. J. Hazard. Mater. 2010, 182, 507-517. [CrossRef]

10. Wen, G.; Zhang, Y.; Zhang, Y.X.; Sun, K.; Chen, Z.Y. Vulcanization characteristics of asphalt/SBS blends in the presence of sulfur. J. Appl. Polym. Sci. 2001, 82, 989-996. [CrossRef]

11. Li, W.C.; Fan, L.; Lin, L.P. Effect of SBS content on performance of modified asphalt. Shandong Transp. Technol. $2009,1,35-37$.

12. Shi, Y.M.; Yang, Q.L.; Pan, C.L.; Cao, S.J.; Liu, Y.L.; Wang, W.L. Feasibility analysis of SBS content determination in modified asphalt based on infrared spectrum. Transp. Technol. 2018, 1, 127-130.

13. Xiao, P.; Kang, A.H.; Liu, P.P. Study on the quantitative performance of modified asphalt by fluorescence microscopy. Pet. Asph. 2005, 19, 45-48.

14. Geng, J.G.; Chang, Q.; Yuan, J.A.; Dai, J.L. Study on crosslinking structure and stability of SBS modified asphalt by GPC. J. Zhengzhou Univ. Eng. 2008, 29, 14-17.

15. Wang, L.H.; Xia, Y. Study on detection method of SBS content in modified asphalt. Chem. Eng. 2012, 2, 24-25.

16. Wang, K. Application of FTIR spectroscopy and artificial neural networks for the quantification of SBS content in modified asphalt. Chem. Resea. Appl. 2018, 30, 1938-1942.

17. Zhong, K.; Cao, D.; Luo, S. Determination the modifier content in SBS modified asphalt based on infrared spectroscopy technique. In Proceedings of the International Conference on Mechanical Engineering and Green Manufacturing (MEGM) 2010, Xiangtan, China, 19-22 November 2010; pp. 1129-1134.

18. Zhang, X.Y. Effect of powder-to-gel ratio on properties of SBS modified asphalt binder. Shandong Transport. Technol. 2016, 2, 109-112.

19. Fu, Y.K.; Zhang, L.; Tan, Y.Q.; Meng, D.Y. Low-Temperature Properties Evaluation Index of Rubber Asphalt; Crc Press-Taylor \& Francis Group: Boca Raton, FL, USA, 2016; p. 16.

20. Chen, J.S.; Liao, M.C.; Shiah, M.S. Asphalt modified by styrene-butadiene-styrene triblock copolymer: Morphology and model. J. Mater. Civ. Eng. 2002, 14, 224-229. [CrossRef]

21. Yan, C.Q.; Huang, W.D.; Xiao, F.P.; Wang, L.F.; Li, Y.W. Proposing a new infrared index quantifying the aging extent of SBSmodified asphalt. Road Mater. Pavement 2017, 1, 1-16. [CrossRef]

22. Masson, J.F.; Pelletier, L.; Collins, P. Rapid FTIR method for quantification of styrene-butadiene type copolymers in bitumen. Appl. Polym. 2001, 79, 959-1149. [CrossRef]

23. Deng, Z.W.; Yu, P.; Chen, L. Application of SPSS software in orthogonal experimental design and results analysis. Comput. Learn. 2009, 5, 15-17.

24. Gong, J.; Shi, P.C.; Li, C.Y. Multivariate analysis of variance using SPSS software. Agric. Net. Infor. 2012, 4, 31-33.

25. Xiao, P.; Kang, A.H.; Li, X.F. Blending mechanism of SBS modified asphalt based on infrared spectroscopy. J. Jiangsu Uni. Nat. Sci. 2005, 26, 529-532. 